For consideration in Biological Conservation

\title{
Geographic and taxonomic patterns of extinction risk in Australian squamates
}

Reid Tingley ${ }^{1}$, Stewart L. Macdonald ${ }^{2}$, Nicola J. Mitchell ${ }^{3}$, John C.Z. Woinarski ${ }^{4}$, Shai Meiri ${ }^{5,6}$, Phil Bowles $^{7}$, Neil A. Cox ${ }^{7}$, Glenn M. Shea ${ }^{8}$, Monika Böhm ${ }^{9}$, Janice Chanson ${ }^{7}$, Marcelo F. Tognelli ${ }^{7}$, Jaclyn Harris ${ }^{1}$, Claire Walke ${ }^{1}$, Natasha Harrison ${ }^{3}$, Savannah Victor ${ }^{3}$, Calum Woods ${ }^{3}$, Andrew P. Amey ${ }^{10}$, Mike Bamford ${ }^{11}$, Gareth Catt ${ }^{12}$, Nick Clemann ${ }^{13}$, Patrick J. Couper ${ }^{10}$, Hal Cogger ${ }^{14}$, Mark Cowan ${ }^{15}$, Michael Craig ${ }^{3,16}$, Chris R. Dickman ${ }^{17}$, Paul Doughty ${ }^{18}$, Ryan Ellis ${ }^{18,19}$, Aaron Fenner ${ }^{20}$, Stewart Ford ${ }^{21}$, Glen Gaikhorst ${ }^{22}$, Graeme R. Gillespie ${ }^{23}$, Matthew J. Greenlees ${ }^{17,24}$, Rod Hobson ${ }^{25}$, Conrad J. Hoskin ${ }^{26}$, Ric How ${ }^{18}$, Mark N. Hutchinson ${ }^{27}$, Ray Lloyd ${ }^{28}$, Peter McDonald ${ }^{29}$, Jane Melville $^{30}$, Damian R. Michael ${ }^{31}$, Craig Moritz ${ }^{32}$, Paul M. Oliver ${ }^{33,34}$, Garry Peterson ${ }^{35}$, Peter Robertson $^{36}$, Chris Sanderson ${ }^{37}$, Ruchira Somaweera ${ }^{38}$, Roy Teale ${ }^{21}$, Leonie Valentine ${ }^{3}$, Eric Vanderduys $^{39}$, Melanie Venz ${ }^{40}$, Erik Wapstra ${ }^{41}$, Steve Wilson ${ }^{10}$, David G. Chapple ${ }^{1^{*}}$

1. School of Biological Sciences, Monash University, Clayton, Victoria Australia

2. CSIRO Land and Water Flagship, Townsville, Queensland, Australia

3. School of Biological Sciences, The University of Western Australia, Crawley, Western Australia, Australia

4. Threatened Species Recovery Hub, National Environmental Science Program, Charles Darwin University, Darwin, Northern Territory, Australia

5. School of Zoology, Tel Aviv University, Tel Aviv, Israel

6. Steinhardt Museum of Natural History, Tel Aviv University, Tel Aviv, Israel

7. Biodiversity Assessment Unit, International Union for Conservation of Nature and Conservation International, Washington DC, USA.

8. Faculty of Veterinary Science, University of Sydney, Sydney, New South Wales, Australia

9. Institute of Zoology, Zoological Society of London, London, UK

10. Natural Environments, Queensland Museum, South Brisbane, Queensland, Australia

11. Bamford Consulting Ecologists, Kingsley, Western Australia, Australia

12. Kanyirninpa Jukurrpa, 18 Panizza Way, Newman, Western Australia, Australia

13. Arthur Rylah Institute for Environmental Research, Department of Environment, Land, Water and Planning, Heidelberg, Victoria, Australia

14. Australian Museum, Sydney, New South Wales, Australia

15. Department of Biodiversity, Conservation and Attractions, Western Australia, Australia

16. School of Veterinary and Life Sciences, Murdoch University, Murdoch, Western Australia, Australia. 
17. School of Life and Environmental Sciences, University of Sydney, Sydney, New South Wales, Australia

18. Department of Terrestrial Zoology, Western Australian Museum, Welshpool, Western Australia, Australia

19. Biologic Environmental Survey, Subiaco, Western Australia, Australia

20. School of Biological Sciences, Flinders University of South Australia, South Australia, Australia

21. Biota Environmental Sciences, Leederville, Western Australia, Australia

22. GHD Consultants, Perth, Western Australia, Australia

23. Flora and Fauna Division, Department of Environment and Natural Resources, Palmerston, Northern Territory, Australia

24. Department of Biological Sciences, Macquarie University, North Ryde, NSW, 2109, Australia.

25. Department of National Parks, Sport and Racing, Queensland, Australia

26. College of Science and Engineering, James Cook University, Townsville, Queensland, Australia

27. Herpetology Section, South Australian Museum, Adelaide, South Australia, Australia

28. Fauna Track, Western Australia, Australia

29. SPREP Pacific Environment, Samoa

30. Department of Sciences, Museums Victoria, Melbourne, Victoria, Australia

31. Institute for Land, Water and Society, Charles Sturt University, Albury, New South Wales, Australia

32. Research School of Biological Sciences and Centre for Biodiversity Analysis, Canberra, Australian Capital Territory, Australia

33. Biodiversity and Geosciences Program, Queensland Museum, Brisbane, Queensland, Australia

34. Environmental Futures Research Institute, School of Environment and Science, Griffith University, Queensland, Australia

35. Department of Environment, Land, Water and Planning, Warrnambool, Victoria, Australia

36. Wildlife Profiles, Hurstbridge, Victoria, Australia

37. School of Biological Sciences, University of Queensland, St Lucia, Queensland, Australia

38. CSIRO Land and Water, Floreat, Western Australia, Australia

39. CSIRO Land and Water, Brisbane, Queensland, Australia

40. Department of Science, Information Technology, Innovation and the Arts, Brisbane, Queensland, Australia

41. School of Biological Sciences, University of Tasmania, Hobart, Tasmania, Australia 
*Corresponding author: Assoc Prof David Chapple, School of Biological Sciences, Monash University, Clayton, Victoria, Australia, Email: David.Chapple@ monash.edu

\section{Acknowledgements}

We thank Toyota, Conservation International, Environment Abu Dhabi, Monash University, the University of Western Australia, and the Department of the Environment and Energy for providing funding for the Australian squamate assessment workshops. We thank A Duran, C Goulet, M Henriksen, and A Naimo for assisting during the workshops, and J Luedtke for facilitating one of the working groups. We thank A Borsboom, D Driscoll, P Horner, B Maryan, R Paltridge, M Pepper, J Smith, M Wynn, J-P Emery, D Bennett, S Sweet, R Shine, J Murphy, F Woods and M Bruton for providing expert advice during the post-workshop review stage. We thank the experts involved in the New Guinea assessment workshop, for their information on species with distributions spanning Torres Strait: M O’Shea, A Allison, O Tallowin, F Parker, A Hamilton, M Read, and M Guinea.
Abstract
Australia is a global hotspot of reptile diversity, hosting 10\% of the world's squamate (snake and lizard) species. Yet the conservation status of the Australian squamate fauna has not been assessed for more than 25 years; a period during which the described fauna has risen by $\sim 40 \%$. Here we provide the first comprehensive conservation assessment of Australian terrestrial squamates using IUCN Red List Categories and Criteria. Most (86.4\%; $\mathrm{n}=819 / 948)$ Australian squamates were categorised as Least Concern, $4.5 \%$ were Data Deficient, and $7.1 \%$ (range 6.8\%-11.3\%, depending on the treatment of Data Deficient species) were threatened (3.0\% Vulnerable, 2.7\% Endangered, 1.1\% Critically Endangered). This level of threat is low relative to the global average ( 18\%). One species (Emoia nativitatis) was assessed as Extinct, and two species (Lepidodactylus listeri and Cryptoblepharus egeriae) are considered Extinct in the Wild: all three were endemic to Christmas Island. Most (75.1\%) threat assessments were based on geographic range attributes, due to limited data on population trends or relevant proxies. Agriculture, fire, and invasive species were the threats that affected the most species, and there was substantial geographic variation in the number of species affected by each threat. Threatened species richness peaked on islands, in the Southern Alps, and across northern Australia. Data deficiency was greatest in northern Australia and in coastal Queensland. Approximately one-in-five threatened species were not represented in a single protected area. Our analyses shed light on the species, regions, and threats in most urgent need of conservation intervention.

Keywords: assessment; conservation status; extinction risk; IUCN; reptiles; threat status 


\section{Introduction}

For over 50 years, the International Union for Conservation of Nature (IUCN) Red List of Threatened Species (IUCN, 2018) has been an important tool for establishing global conservation priorities. However, even among terrestrial vertebrates - the world's most intensively studied group of species-25.6\% of currently recognized taxa have not been evaluated against the IUCN Red List Categories and Criteria (IUCN, 2018). Within terrestrial vertebrates, estimates of extinction risk are primarily based on studies of birds, mammals, and amphibians; indeed, only $\sim 64 \%$ of the world's $\sim 11,000$ reptile species have published extinction risk assessments (IUCN, 2018). This is despite evidence of ongoing reptile declines globally (Huey et al., 2009; Sinervo et al., 2010; Tingley et al., 2016). A recent analysis of global time series data, for example, estimated an average decline in reptile populations of 54-55\% (Saha et al., 2018). Of those reptile species that have been assessed for the IUCN Red List (7,023 species), 18\% are assessed as threatened (meeting criteria for Vulnerable, Endangered, or Critically Endangered), and 15\% considered Data Deficient (IUCN, 2018).

Here we provide the first comprehensive assessment of the extinction risk of Australian terrestrial squamates (snakes and lizards) using IUCN criteria; the first such assessment of this group in $>25$ years (Cogger et al., 1993). Australia is a hotspot of squamate diversity ( 1,020 species; 807 lizard species, 213 snake species), hosting $\sim 10 \%$ of the world's squamate species (Uetz et al., 2019); yet, prior to our assessment, Australia was the biogeographic realm with the lowest percentage $(15 \%)$ of squamate species assessed by the IUCN (Meiri and Chapple, 2016), and most of these species were assessed using an older version of the IUCN Red List criteria. This 'assessment' gap mirrors a chronic knowledge gap, with the biggest conservation challenge for the Australian squamate fauna being a lack of information on population sizes and trends (Woinarski, 2018). The richness of the known Australian squamate fauna has increased by approximately $38 \%$ (from 738 to 1,020 species, as of 2018) over the past 25 years, with an average growth rate of $\sim 11$ new species described per year (Cogger et al., 1993; Uetz et al., 2019), and we are still evaluating the number of species that actually occur in Australia. In addition, we have limited understanding of the threats facing each species (Webb et al., 2015; Woinarski et al., 2018), and the extent to which threatened squamates are conserved by Australia's network of protected areas (Lunney et al., 2017; Watson et al., 2011). Collectively, these issues have hampered efforts to assess the conservation status of the Australian squamate fauna and hence to prioritise and enact appropriate conservation management.

Our comprehensive assessment of Australian terrestrial squamates represents a major step towards addressing this knowledge gap, as we use the resulting data to: (i) elucidate key threats to Australian squamates; (ii) evaluate whether there are geographic and taxonomic biases in those threats, as well as in threatened and Data Deficient species richness; (iii) assess the extent to which the distributions of squamate species overlap with the Australian protected area network; and (iv) compare key threats, 
extinction risk, and data deficiency between Australian squamates and other Australian terrestrial vertebrate groups. We anticipate that our study will draw attention to species of conservation concern and spur targeted research and management on Australia's threatened, Near Threatened, and Data Deficient squamate species, thereby greatly improving our knowledge of, and conservation efforts for, this diverse group.

\section{Methods}

\subsection{IUCN Red List Categories and Criteria}

The IUCN Red List of Threatened Species is based on five criteria that relate to different indicators of extinction risk: rate of population decline (Criterion A); restricted geographic range and decline/fragmentation (Criterion B); small population size and decline (Criterion C); very small or restricted populations (Criterion D); and probability of extinction from quantitative analysis (Criterion E) (IUCN, 2012). Red List assessments for each species typically involve collating available published data on these indicators, which are subsequently evaluated by experts in regional or taxonomic workshops. This evaluation serves three functions: to obtain further, often unpublished, information relevant to these indicators; to compare the resulting data against quantitative thresholds to determine whether a species warrants listing in any of the three 'threatened' categories (Vulnerable, Endangered, or Critically Endangered); and to identify further research priorities and conservation measures. Species accounts and maps are then reviewed post-workshop (by IUCN staff in collaboration with experts) to ensure consistency in the application of the categories and criteria, with the agreed final global conservation status published on the IUCN Red List (www.iucnredlist.org).

\subsection{Australian squamate workshops}

Two five-day IUCN workshops were held in Australia to assess the extinction risk of Australian terrestrial squamates against IUCN criteria; in Perth (February 2017) and in Melbourne (June 2017). Marine and freshwater turtles, crocodiles, and sea-snakes were not evaluated, as these are assessed separately by taxa-focused IUCN Species Survival Commission Specialist Groups. Here we further restrict our analyses to terrestrial and freshwater squamates; i.e. we excluded species that were listed as occupying marine habitats, freshwater and marine habitats, or terrestrial and marine habitats (as listed in the 'systems' field recorded by the IUCN). We also excluded the three introduced squamates now present on the Australian mainland and/or adjacent islands (Asian house gecko Hemidactylus frenatus, the common sun skink Eutropis multifasciata, and the flowerpot blind snake Indotyphlops braminus), as well as introduced squamates whose Australian range is restricted to Christmas Island and the Cocos (Keeling) islands (Lycodon capucinus, Lygosoma bowringi, Gehyra mutilata, Lepidodactylus lugubris). Our final species list included 948 species, of which almost all (98.7\%) are endemic to Australia and its island territories (see Table S1 for a list of species). 
183 Each workshop involved coordinators, spatial analysts, IUCN facilitators, and approximately 25 experts who had knowledge of the species being assessed. Prior to the workshops, IUCN staff collated basic data (e.g., geographic range, population abundance, habitat and ecology, threats, conservation measures, and relevant bibliographic information for sources) on each species from existing literature and entered it into the IUCN's Species Information Service (SIS) database. The pre-entered information was reviewed by workshop participants during the workshops and modified as needed. Following agreement on the supporting information by participants, the IUCN Red List Categories and Criteria (IUCN 2012) were applied to each species, and this was recorded in SIS. All assessments were reviewed and accepted by the IUCN, and published on the Red List website (www.iucnredlist.org) during 2018.

\subsection{Species distribution data}

Occurrence data for all native Australian terrestrial squamate species were collated from various sources, including museums, State and Federal Government Departments, citizen science programs, and academic researchers. These data were transformed to a common geographic coordinate system (WGS84). All records with missing geographic coordinates were removed. Records were reclassified so that they adhered to a common taxonomy following the Australian Society of Herpetologists official species list (available from http://www.australiansocietyofherpetologists.org/positionstatements).

Experts subsequently reviewed all distribution maps at the two workshops. For each species, experts were presented with a printed geographic range map consisting of the collated occurrence records, a minimum convex polygon encompassing those records (the minimum extent of occurrence of each species), and an expert-derived range map from the Australian Reptile Online Database (AROD; http://www.arod.com.au/arod), overlaid on a Google Maps base map. Experts then deleted or added records on the maps where appropriate. One dedicated spatial analyst in each working group then amended the AROD range polygon in real-time with the experts using custom software. The result of this process was a refined geographic range polygon for each species, converted to a shapefile and clipped to the Australian coastline. These spatial data are available from https://www.iucnredlist.org/.

\subsection{Estimating overall extinction risk}

Species classified as Data Deficient introduce uncertainty into calculations of the percentage of threatened species (i.e. those classified as Vulnerable, Endangered, or Critically Endangered). We therefore estimated the percentage of threatened species using three different approaches to the treatment of Data Deficient species, following Böhm et al. (2013). 
219 First, we assumed that the true extinction risk of Data Deficient species would fall into the three

220 threatened categories in the same proportions as observed in currently assessed species:

$221(\mathrm{CR}+\mathrm{EN}+\mathrm{VU}) /(\mathrm{N}-\mathrm{DD})$, where $\mathrm{N}$ is the total number of Australian squamate species, and $\mathrm{CR}, \mathrm{EN}$,

222 VU, and DD are the numbers of Critically Endangered, Endangered, Vulnerable, and Data Deficient

223 species, respectively. Second, we produced an optimistic (lower bound) estimate of the percentage of

224 threatened species by assuming that no Data Deficient species were threatened: $(\mathrm{CR}+\mathrm{EN}+\mathrm{VU}) / \mathrm{N}$.

225 Finally, we produced a pessimistic estimate by assuming that all Data Deficient species were

226 threatened: $(\mathrm{CR}+\mathrm{EN}+\mathrm{VU}+\mathrm{DD}) / \mathrm{N}$. We also report the number of Extinct and Extinct in the Wild

227 species, but do not include these species in estimates of the numbers of threatened species, nor in our

228 spatial analyses.

229

230 Population trajectories for each species were categorised as stable, increasing, decreasing, or

231 unknown, based on published reports and expert assessments of population trends.

232

233

\subsection{Geographic and taxonomic patterns of extinction risk}

234

Species geographic range maps were overlaid on a $25 \mathrm{~km}$ x $25 \mathrm{~km}$ grid to estimate spatial patterns of

235

236

species richness. This was done for (i) all squamate species; (ii) threatened species (using both

237 optimistic and pessimistic estimates of the number of threatened species, as described in 2.4); and (iii)

238 Data Deficient species. We mapped the absolute numbers and the proportions of threatened and Data Deficient species in each grid cell. We also calculated an alternative approach to visualise geographic patterns of threat, in which we converted the IUCN Red List categories into a continuous score, whereby $\mathrm{LC}=0, \mathrm{NT}=1, \mathrm{VU}=2, \mathrm{EN}=3$, and $\mathrm{CR}=4$. We present sums and means of those scores for each $25-\mathrm{km}$ grid cell. For example, if six species were present in a grid cell, of which four were LC, 1 was VU and 1 was EN, the sum for that cell would be $5((4 * 0)+(1 * 2)+(1 * 3))$, whereas the weighted mean would be $0.83(5 / 6)$. The latter approach accounted for overall species richness in a cell. We repeated all the above analyses at $1 \mathrm{~km}$ resolution for Christmas Island, Lord Howe Island (group), and Norfolk Island (group). This finer spatial resolution was used to better visualise geographic patterns, given the relatively small spatial extent of the islands. We also evaluated whether threatened species were randomly distributed among snakes and lizards, and among families using Fisher's Exact Tests, with p-values computed via Monte Carlo simulation.

\subsection{Threatening processes}

251 Major threats were assigned for every species by experts at the workshops. We used this threat information to map the number and proportion of species threatened by agriculture (IUCN threat type 2), fire and fire suppression (IUCN threat type 7.1), and invasive and other problematic species and diseases (IUCN threat type 8.1, 8.2 and 8.4; no species were classified under the other threat 8 
subcategories). We did this for all species irrespective of IUCN status, and for only threatened species (omitting Data Deficient species).

\subsection{Protected area coverage}

We examined the extent to which squamate species were likely to be present in the Australian protected area network, using all 10, 778 available protected areas (IUCN protected area categories IVI) contained in the 2016 version of the Collaborative Australian Protected Area Database (https://www.environment.gov.au/land/nrs/science/capad/2016). We estimated the proportion of each species' estimated range that overlapped the protected area network, as well as the number of species (total and threatened), that: (i) did not overlap with any protected area; and (ii) had $\leq 10 \%$ of their geographic range within the protected area network. To provide upper and lower bounds on these calculations for threatened and non-threatened species, we either assumed that Data Deficient species were non-threatened (optimistic) or threatened (pessimistic), as above. We used a Wilcoxon Rank Sum Test to examine whether there was a difference between the median proportion of a species' geographic range within protected areas between threatened and non-threatened species. All analyses were conducted in R v3.5.2 ( $\mathrm{R}$ Core Team, 2018).

\section{Results}

\subsection{Overall extinction risk}

Based on the results of the assessment workshops, 819 (86.4\%) Australian squamate species were assessed as Least Concern (Table 1). Nineteen species (2.0\%) were classified as Near Threatened. In the threatened categories, 28 (3.0\%) species were Vulnerable, 26 (2.7\%) were Endangered, and 10 (1.1\%) were Critically Endangered. One species (Emoia nativitatis) was considered to have recently become extinct, and two species (Lepidodactylus listeri and Cryptoblepharus egeriae) were assessed as Extinct in the Wild. Additionally, 43 (4.5\%) species were classified as Data Deficient (see Table S2 for a list of Data Deficient species). Assuming all Data Deficient species will be assigned to threatened categories in the same proportions as non-Data Deficient species, the total percentage of threatened (Vulnerable, Endangered or Critically Endangered) Australian squamates is 7.1\%. Optimistic and pessimistic estimates are $6.8 \%$ and $11.3 \%$, respectively. Population trends were assessed as stable for $59.2 \%(n=561)$ of species, decreasing for $6.3 \%(n=60)$, and unknown for $34.2 \%$ $(n=324)$.

Most species $(68.7 \% ; \mathrm{n}=57)$ that were classified in a more imperilled status than Least Concern (i.e. Near Threatened-Critically Endangered) were classified as such based largely on having a restricted geographic range (typically less than $20,000 \mathrm{~km}^{2}$ ) with an ongoing threat that reduces this distribution, or the quality of habitat within it (IUCN Criterion B). Including in this category those species also listed under criterion D2 (restricted area of occupancy or few locations, with a highly 
292

293

294

295

296

297

298

299

300

301

302

303

304

305

306

307

308

309

310

311

312

313

314

315

316

317

318

319

320

321

322

323

324

325

326

327

328

plausible near-future threat) increases the total percentage of species classified on the basis of their geographic range to $75.1 \%(\mathrm{n}=72)$. Indeed, geographical range sizes of threatened species were considerably smaller than those of non-threatened species (Fig. 1). Three species (3.6\%) were listed under both D criteria (few mature individuals in addition to the D2 criteria noted above). A further $6.0 \%$ of species $(n=5)$ were classified solely due to severe $(>30 \%)$ reductions in population size over the last ten years or three generations (Criterion A). Only one threatened species (Liopholis kintorei) was classified as threatened based entirely on its small population size and population decline (Criterion C). The remaining two species were classified as threatened using a combination of B and C (Simalia oenpelliensis), and C and D (Bellatorias obiri) criteria.

\subsection{Geographic and taxonomic patterns of extinction risk}

Squamate species richness was highest in the Wet Tropics of north-eastern Australia, in the Kimberley and Pilbara regions of Western Australia, and in central Australia (Fig. 2). Geographic patterns of threat were largely congruent when summarised using different metrics. Total threatened species richness was highest in the Alps of south-eastern Australia, and in northern Australia, with a particularly high number of threatened species in the vicinity of Kakadu National Park and across the Kimberley region (Fig. 3A\&C). South-western Australia also hosted high total threatened species richness. Similar geographic patterns were evident when controlling for total species richness, except that controlling for species richness emphasised threats facing squamates on Australia's island territories (Fig. 3B\&D). Christmas Island, the Norfolk Island group, and the Lord Howe Island group each hosted two species (total $n=4$ species), all of which were threatened (see insets of Fig. 3). Christmas Island was also the only known location for the one species assessed as extinct (Emoia nativitatis), and the two species that were considered Extinct in the Wild (Lepidodactylus listeri and Cryptoblepharus egeriae). The sum and mean of IUCN scores showed similar relative geographic patterns to total species richness (Fig. 3A\&C cf. Fig. 3E) and proportional species richness (Fig. 3B\&D cf. Fig. 3F), respectively.

Assuming that no Data Deficient species were threatened, we found no evidence of overall bias at the level of taxonomic family $(P=0.61$; Table 2$)$ or suborder $(P=0.13)$. Similarly, when assuming that all Data Deficient species were threatened, we found no evidence of overall bias at the level of taxonomic family $(P=0.44$; Table 2$)$ or suborder $(P=0.89)$. We found qualitatively similar results when excluding families with fewer than five species (Acrochordidae, Colubridae, Homalopsidae, Natricidae).

Although there was no evidence of taxonomic bias overall, some families possessed high proportions of threatened species, with carphodactylid geckos being the most threatened, followed by pygopodid geckos and skinks (Table 2). It is interesting to note that Carphodactylidae and Pygopodidae are the 
only two regionally endemic families. Assuming all Data Deficient species are threatened led to a large increase in the percentage of threatened blind snakes (Typhlopidae).

Data deficiency was highest near the Kimberley region, with secondary hotspots in coastal Queensland and across the Northern Territory (Fig. 4A). The Kimberley region remained a hotspot of data deficiency when controlling for total species richness (Fig. 4B).

\subsection{Threatening processes}

Invasive and other problematic species and diseases were the most prevalent threats to Australian squamates ( $14.6 \%$ of species; $n=138)$, followed closely by agriculture $(12.4 \% ; n=118)$. Natural system modifications affected $9.3 \%$ of species; fire and fire suppression (threat type 7.1 ) affected $90 \%$ $(n=79)$ of species within this broader category. Other notable threats included biological resource use (4.4\%; $n=42)$, including hunting ( $n=33)$ and logging $(n=9)$, energy production and mining $(4.1 \%$; $\mathrm{n}=39)$, and climate change and severe weather events $(3.8 \% ; \mathrm{n}=36)$.

Effects of agriculture were most pronounced in eastern and south-western portions of the country (Fig. 5A\&B), whereas effects of fire and fire suppression were more geographically heterogenous and widespread (Fig. 5C\&D). Numerous species across northern Australia, Queensland, and the Alps were impacted by invasive species (Fig. 5E); accounting for species richness highlighted additional hotspots in western Victoria and Tasmania (Fig. 5F). All species that were endemic to Christmas Island, or to the Norfolk and Lord Howe Island Groups, were threatened by invasive species.

Geographic variation in threatening processes was similar when considering only threatened species. However, compared to squamates overall, fewer threatened squamates were impacted by agriculture and fire in south-western Australia, and by fire and invasive species in Queensland (Fig. S1).

\subsection{Protected area coverage}

Across all 945 assessed species (excluding three species classified as Extinct/Extinct in the Wild), distributions of $3.7 \%(n=35)$ were completely outside Australia's protected area network. Representation was not equally distributed among threatened and non-threatened species, however. Between $17.2 \%$ (optimistic; $n=11$ ) and $21.5 \%$ (pessimistic; $n=23$ ) of threatened species were not represented in a single protected area, compared to $2.7 \%(n=24)-1.4 \%(n=12)$ of non-threatened species. Roughly one quarter $(24.1 \% ; n=228)$ of species had less than $10 \%$ of their distribution in the protected area network $(31.3 \%-39.3 \%$ of threatened species; $23.6 \%-22.2 \%$ of non-threatened species). 
365

366

367

368

369

370

371

372

373

374

375

376

377

378

379

380

381

382

383

384

385

386

387

388

389

390

391

392

393

394

395

396

397

398

399

400

401

Conclusions regarding differences in the extent to which threatened and non-threatened species were protected by the network were sensitive to the treatment of Data Deficient species. When Data

Deficient species were assumed to be non-threatened, threatened species' distributions overlapped to a greater extent with protected areas than did the distributions of non-threatened species (median overlap for threatened species $=32.2 \%$; non-threatened species $=17.8 \%: \mathrm{W}=23848, p=0.04$ ); however, the opposite was true when assuming that Data Deficient species were threatened (threatened species $=15.2 \%$; non-threatened species $=18.0 \% ; \mathrm{W}=44483, p=0.9$ ). Nonetheless, there was substantial variation within each group in both cases, particularly for threatened species. Over one-quarter (27.9\%) of Data Deficient species did not occur in a protected area, and the distributions of $51.2 \%$ of Data Deficient species had $<10 \%$ overlap with the protected area network. Threatened and Data Deficient species that do not overlap a single protected area are provided in Table S3.

\section{Discussion}

Our analysis of the conservation status of Australian terrestrial squamates documents how their plight has deteriorated over the past 25 years, with the proportion of species assessed as threatened nearly doubling from 1993 (Cogger et al., 1993) to 2017 (this study). As the number of recognized squamate species has grown substantially during this period (by nearly $40 \%$ ), this equates to a doubling of the number of threatened species from 32 to 64 . Alarmingly, the last decade has seen the first documented extinction of an Australian squamate (the Christmas Island forest skink, Emoia nativitatis: last recorded in the wild in 2010), and two other Christmas Island species becoming extinct in the wild (blue-tailed skink, Cryptoblepharus egeriae: last wild record in 2010; Lister's gecko, Lepidodactylus listeri: last wild record in 2012; Andrew et al., 2018). In addition, no squamate species that was considered threatened in 1993 has improved its conservation status to an extent that it is no longer considered threatened.

\subsection{Australian squamates have a lower proportion of threatened species than the global average} Our 2017 assessments revealed that $7.1 \%$ of Australian terrestrial squamates are threatened with extinction. This percentage is substantially lower than the global average for reptiles (18\% as of April 2019; IUCN 2019), and for Australian terrestrial mammals (9\% extinct, 18.5\% threatened) and frogs ( $1.7 \%$ extinct, $12.1 \%$ threatened), although it is higher than for Australian terrestrial birds (1.2\% extinct, $5.3 \%$ threatened). However, the proportion of threatened species is similar to that reported for South African reptiles (5.4\%; Tolley et al., 2019). To some extent, the relatively low percentage of threatened Australian terrestrial squamates may simply reflect our limited knowledge and understanding of the population sizes and trends of this group, and the threats to which they are exposed (Doherty et al., 2015; Webb et al., 2015; Woinarski et al., 2018), rather than a lower degree of imperilment. 
403 One quarter of all Australian terrestrial squamates have an extent of occurrence smaller than 20,000

404

405

406

407

408

409

410

411

412

413

414

415

416

417

418

419

420

421

422

423

424

425

426

427

428

429

430

431

432

433

434

435

436

437

438

$\mathrm{km}^{2}$ (i.e. the Red List threshold for being eligible for being considered Vulnerable; IUCN, 2012), and therefore improved knowledge of the threats impacting specific species has the potential to push many species from Least Concern, Data Deficient, or Near Threatened into a threatened category under Criterion B. This is a realistic possibility: although only $6.3 \%$ of species were reported as declining, the population trend for a third of all Australian squamate species is currently unknown. In addition, many of the known population trends were estimated from expert opinion, which may overlook real declines. The fact that Data Deficient species have geographical range sizes comparable to those of threatened species (Fig. 1) suggests that many Data Deficient species, in particular, may be at high risk of extinction.

Clear geographic biases were evident in the distributions of threatened squamates. Geographic hotspots of threat have been reported for reptiles at both local (New Zealand: Tingley et al., 2013; Africa: Tolley et al., 2016) and global scales (Böhm et al., 2013; Maritz et al., 2016). The locations of threat hotspots for Australian squamates coincide with the increased prevalence of key threatening processes, such as land clearing (south-western Western Australia, south-eastern Australia, Queensland) and invasive predators and competitors (northern Australia, alpine region, offshore islands) (Fig. 5). Offshore islands are also hotspots for threatened terrestrial birds (notably Christmas, Norfolk, and Lord Howe), as is south-eastern Australia (Garnett et al., 2011; Geyle et al., 2018).

Hotspots of threatened squamate richness differ from amphibian and mammal threat hotspots, however. Threatened amphibians are predominantly clustered along the coast of northern New South Wales and southern Queensland, and in the Wet Tropics (IUCN, 2018). In contrast, mammal losses have been associated mainly with introduced predators that have extensive ranges across the Australian mainland, and thus mammal extinction risk is more spatially homogenous compared to other vertebrate groups (Burbidge et al., 2009; Woinarski et al., 2015, 2014).

Worldwide, the majority (73 of 82; 89\%) of recorded Quaternary reptile extinctions have been of island endemics (Slavenko et al., 2016). This pattern is clearly evident in Australian squamates. In addition to the three Extinct or Extinct in the Wild species on Christmas Island, all endemic squamate species on that island $(\mathrm{n}=2)$, and other offshore islands (Norfolk Island group, Lord Howe Island group; two species present on both island groups), are listed as threatened (Fig. 4). The Christmas Island reptile fauna suffered the most spectacular of these losses, largely due to catastrophic declines since the 1980s. The introduced wolf snake (Lycodon capucinus) is thought to have been a major driver of these declines, with non-native yellow crazy ants (Anoplolepis gracilipes), cats (Felis catus), rats (Rattus rattus), and centipedes (Scolopendra subspinipes) also being suspected as major threats.
While the literature is mostly a record of loss, we recognise that intensive management (through 
capture of individuals from the rapidly dwindling wild populations, and establishment of a successful captive breeding program) has been instrumental in averting the extinction of an endemic skink and an endemic gecko (Andrew et al., 2018). Continuing intensive conservation efforts, especially biosecurity, will be required to ensure the persistence of native squamate species on all Australian offshore islands.

Interestingly, we detected no evidence of overall taxonomic bias in conservation status among Australian terrestrial squamates, although some families are clearly over-represented among threatened species (e.g., Carphodactylidae). This is in contrast to most other studies of reptile extinction risk, which have demonstrated that a species' susceptibility to extinction is non-random (Böhm et al., 2016b; Reed and Shine, 2002; Tingley et al., 2013), and that elevated extinction risk is clustered within particular taxonomic groups (Böhm et al., 2013; Tonini et al., 2016; Tolley et al., 2016). This may reflect a true uniformity of threat for Australian squamates; alternatively, it could simply be an artefact of incomplete knowledge of taxonomy and population trends (Woinarski, 2018), or due to the fact that familial divisions in reptiles are relatively coarse. As clear taxonomic biases exist in regard to where suspected species complexes occur (as outlined in the taxonomic notes in the Red List assessments), and newly described species possess traits that are more likely to result in their being listed as threatened species (Meiri, 2016), increased knowledge of the biodiversity of Australian squamates may result in the future detection of taxonomic biases in threat.

\subsection{High rates of Data Deficiency relative to other Australian terrestrial vertebrates}

Forty-three Australian squamate species (4.5\%) were classified as Data Deficient (Table S1). This level of Data Deficiency is relatively low compared to the global average for reptiles (15\%; IUCN 2019); however, the number of Data Deficient Australian squamates that lack information on population status and trends ( $86 \%$ ) is comparable to the same figure for squamates globally $(97 \%$ including Australian species; IUCN, 2018). Thus, despite the relatively low percentage of Data Deficient species found here, conservation of the Australian squamate fauna is clearly impeded by a lack of critical information on population sizes and trends. This not only impedes assessment of species under Criterion A, but also implies a lack of long-term knowledge of biology, ecology and threatening processes, which further limits the potential to assess species against Criteria B-E. Indeed, according to IUCN assessments, squamates have the highest proportion of Data Deficient species of any Australian terrestrial vertebrate group (mammals: $1.3 \%$, birds: $0 \%$, frogs: $0 \%$ ).

Levels of Data Deficiency in squamates were particularly high in tropical northern Australia (Kimberley region, Northern Territory, northern Queensland). This lack of knowledge on the squamates of northern Australia is likely due to its relative remoteness and inaccessibility, its diverse reptile fauna, and substantial ongoing taxonomic reappraisal for many groups from this region 
476 (Rosauer et al., 2016). Targeted research should continue across northern Australia to fill this

477 substantial knowledge gap.

\subsection{Invasive species and habitat loss are key threats to Australian squamates}

480

The major threats to Australian squamates are invasive species (predators and competitors, such as

481 cats (Felis catus) and rats (Rattus rattus); and toxic cane toads (Rhinella marina), habitat loss or modification (agriculture, urbanisation, altered fire regimes, mining activities), biological resource use, and climate change. These threats are consistent with those that have been identified for reptiles at both local (e.g. South Africa: habitat loss and modification; Tolley et al., 2019) and global scales (e.g. habitat loss, harvesting, climate change; Böhm et al., 2016a, 2013; Sinervo et al., 2010). Indeed, these threats are generally the same as those identified for Australian reptiles 25 years ago (Cogger et al., 1993), although there has been an increase in the number of species recorded as impacted by invasive species (cane toads, weeds, predators) and climate change. With regard to invasive species, the extent of the threat posed by introduced predators, particularly feral cats (Felis catus), has undoubtedly been underestimated until recently (Doherty et al., 2015). For instance, Woinarski et al. (2018) estimated that $\sim 649$ million Australia reptiles are killed each year (or 1.8 million per day) by cats, most of which are feral. However, habitat loss continues to be a key threatening process in Australia, as the country has one of the highest rates of land clearing in the world $(\sim 395,000$ ha per year in Queensland; Webb et al., 2015), with most clearing occurring and continuing in Queensland (Bradshaw, 2012). The threats facing Australian reptiles largely mirror those facing other Australian vertebrate groups (Garnett and Crowley, 2000; Woinarski et al., 2015, 2014).

\subsection{Threatened and Data Deficient squamates are poorly represented by the protected area} network

We found that the distributions of many threatened and Data Deficient squamate species showed low spatial congruence with Australia's protected areas. This finding may reflect the fact that threatened and Data Deficient species have, on average, more restricted distributions than non-threatened species (Fig. 1); however, it is consistent with that reported for South African reptiles (Tolley et al., 2019). The low representation of Data Deficient species in protected areas explains why the distributions of threatened species overlapped with protected areas to a lesser extent when we assumed that Data Deficient species were threatened, compared to when we assumed that they were non-threatened. It is important to note, however, that IUCN range maps are generalised range maps and thus often depict the suspected range of a species, and not actual localities where the species occurs (which are unknown for nearly all Australian squamates). Thus, the extent to which species' ranges overlap with protected areas (or other landscape features) should be interpreted with caution. It is anticipated that

511 the quality of IUCN range maps will be improved in the near future through the ongoing development

512 of Extent of Suitable Habitat maps, which will provide more refined representations of species 
distributions. An additional caveat of our findings is that population persistence is not necessarily guaranteed just because a species occurs in one or more protected areas (Kearney et al., 2018). Nonetheless, our analysis represents an initial first-step toward understanding existing conservation measures for Australian terrestrial squamates. Future studies could usefully examine the optimal placement of additional protected areas using the distribution data collated here, in a similar fashion to a recent analysis for threatened Australian mammals (Ringma et al., 2019).

\section{Conclusions}

The 25-year period since the last national assessment of Australian squamates (Cogger et al., 1993) has seen a marked deterioration of their conservation status, highlighted by three species being assessed as Extinct or Extinct in the Wild, a doubling in the number of recognised threatened species, and an expansion of the number of threats impacting native species. Although intensive taxonomic study over the past few decades has increased the size of the described Australian terrestrial squamate fauna by $\sim 38 \%$, substantial research effort needs to continue to uncover the true diversity. The rapidly expanding list of known species, combined with the remoteness/inaccessibility of many areas, has resulted in poor knowledge of distributions, biology, ecology, threats, and population trends. Thus, targeted studies are urgently needed on the threatened, Near Threatened, and Data Deficient species recognised here.

\section{References}

Andrew, P., Cogger, H., Driscoll, D., Flakus, S., Harlow, P., Maple, D., Misso, M., Pink, C., Retallick, K., Rose, K., Tiernan, B., West, J., Woinarski, J.C.Z., 2018. Somewhat saved: a captive breeding programme for two endemic Christmas Island lizard species, now extinct in the wild. Oryx 52, 171-174. https://doi.org/DOI: 10.1017/S0030605316001071

Böhm, M., Collen, B., Baillie, J.E.M., Bowles, P., Chanson, J., Cox, N., Hammerson, G., Hoffmann, M., Livingstone, S.R., Ram, M., Rhodin, A.G.J., Stuart, S.N., van Dijk, P.P., Young, B.E., Afuang, L.E., Aghasyan, A., García, A., Aguilar, C., Ajtic, R., Akarsu, F., Alencar, L.R.V., Allison, A., Ananjeva, N., Anderson, S., Andrén, C., Ariano-Sánchez, D., Arredondo, J.C., Auliya, M., Austin, C.C., Avci, A., Baker, P.J., Barreto-Lima, A.F., Barrio-Amorós, C.L., Basu, D., Bates, M.F., Batistella, A., Bauer, A., Bennett, D., Böhme, W., Broadley, D., Brown, R., Burgess, J., Captain, A., Carreira, S., Castañeda, M.D.R., Castro, F., Catenazzi, A., CedeñoVázquez, J.R., Chapple, D.G., Cheylan, M., Cisneros-Heredia, D.F., Cogalniceanu, D., Cogger, H., Corti, C., Costa, G.C., Couper, P.J., Courtney, T., Crnobrnja-Isailovic, J., Crochet, P.-A., Crother, B., Cruz, F., Daltry, J.C., Daniels, R.J.R., Das, I., de Silva, A., Diesmos, A.C., Dirksen, L., Doan, T.M., Dodd, C.K., Doody, J.S., Dorcas, M.E., Duarte de Barros Filho, J., Egan, V.T., El Mouden, E.H., Embert, D., Espinoza, R.E., Fallabrino, A., Feng, X., Feng, Z.-J., Fitzgerald, L., Flores-Villela, O., França, F.G.R., Frost, D., Gadsden, H., Gamble, T., Ganesh, S.R., Garcia, 
M. a., García-Pérez, J.E., Gatus, J., Gaulke, M., Geniez, P., Georges, A., Gerlach, J., Goldberg, S., Gonzalez, J.-C.T., Gower, D.J., Grant, T., Greenbaum, E., Grieco, C., Guo, P., Hamilton, A.M., Hare, K., Hedges, S.B., Heideman, N., Hilton-Taylor, C., Hitchmough, R., Hollingsworth, B., Hutchinson, M., Ineich, I., Iverson, J., Jaksic, F.M., Jenkins, R., Joger, U., Jose, R., Kaska, Y., Kaya, U., Keogh, J.S., Köhler, G., Kuchling, G., Kumlutaş, Y., Kwet, A., La Marca, E., Lamar, W., Lane, A., Lardner, B., Latta, C., Latta, G., Lau, M., Lavin, P., Lawson, D., LeBreton, M., Lehr, E., Limpus, D., Lipczynski, N., Lobo, A.S., López-Luna, M. a., Luiselli, L., Lukoschek, V., Lundberg, M., Lymberakis, P., Macey, R., Magnusson, W.E., Mahler, D.L., Malhotra, A., Mariaux, J., Maritz, B., Marques, O. a. V., Márquez, R., Martins, M., Masterson, G., Mateo, J. a., Mathew, R., Mathews, N., Mayer, G., McCranie, J.R., Measey, G.J., MendozaQuijano, F., Menegon, M., Métrailler, S., Milton, D. a., Montgomery, C., Morato, S. a. a., Mott, T., Muñoz-Alonso, A., Murphy, J., Nguyen, T.Q., Nilson, G., Nogueira, C., Núñez, H., Orlov, N., Ota, H., Ottenwalder, J., Papenfuss, T., Pasachnik, S., Passos, P., Pauwels, O.S.G., PérezBuitrago, N., Pérez-Mellado, V., Pianka, E.R., Pleguezuelos, J., Pollock, C., Ponce-Campos, P., Powell, R., Pupin, F., Quintero Díaz, G.E., Radder, R., Ramer, J., Rasmussen, A.R., Raxworthy, C., Reynolds, R., Richman, N., Rico, E.L., Riservato, E., Rivas, G., da Rocha, P.L.B., Rödel, M.-O., Rodríguez Schettino, L., Roosenburg, W.M., Ross, J.P., Sadek, R., Sanders, K., SantosBarrera, G., Schleich, H.H., Schmidt, B.R., Schmitz, A., Sharifi, M., Shea, G., Shi, H.-T., Shine, R., Sindaco, R., Slimani, T., Somaweera, R., Spawls, S., Stafford, P., Stuebing, R., Sweet, S., Sy, E., Temple, H.J., Tognelli, M.F., Tolley, K., Tolson, P.J., Tuniyev, B., Tuniyev, S., Üzüm, N., van Buurt, G., Van Sluys, M., Velasco, A., Vences, M., Veselý, M., Vinke, S., Vinke, T., Vogel, G., Vogrin, M., Vogt, R.C., Wearn, O.R., Werner, Y.L., Whiting, M.J., Wiewandt, T., Wilkinson, J., Wilson, B., Wren, S., Zamin, T., Zhou, K., Zug, G., 2013. The conservation status of the world's reptiles. Biol. Conserv. 157, 372-385. https://doi.org/10.1016/j.biocon.2012.07.015

Böhm, M., Cook, D., Ma, H., Davidson, A.D., García, A., Tapley, B., Pearce-Kelly, P., Carr, J., 2016a. Hot and bothered: Using trait-based approaches to assess climate change vulnerability in reptiles. Biol. Conserv. 204, 32-41. https://doi.org/https://doi.org/10.1016/j.biocon.2016.06.002 Böhm, M., Williams, R., Bramhall, H.R., McMillan, K.M., Davidson, A.D., Garcia, A., Bland, L.M., Bielby, J., Collen, B., 2016b. Correlates of extinction risk in squamate reptiles: the relative importance of biology, geography, threat and range size. Glob. Ecol. Biogeogr. 25, 391-405. https://doi.org/10.1111/geb.12419

Bradshaw, C.J.A., 2012. Little left to lose: deforestation and forest degradation in Australia since European colonization. J. Plant Ecol. 5, 109-120. https://doi.org/10.1093/jpe/rtr038 Burbidge, A.A., McKenzie, N.L., Brennan, K.E.C., Woinarski, J.C.Z., Dickman, C.R., Baynes, A., Gordon, G., Menkhorst, P.W., Robinson, A.C., 2009. Conservation status and biogeography of Australias terrestrial mammals. Aust. J. Zool. 56, 411-422. 
Doherty, T.S., Davis, R.A., van Etten, E.J.B., Algar, D., Collier, N., Dickman, C.R., Edwards, G., Masters, P., Palmer, R., Robinson, S., 2015. A continental-scale analysis of feral cat diet in Australia. J. Biogeogr. 42, 964-975. https://doi.org/10.1111/jbi.12469

Geyle, H.M., Woinarski, J.C.Z., Baker, G.B., Dickman, C.R., Dutson, G., Fisher, D.O., Ford, H., Holdsworth, M., Jones, M.E., Kutt, A., Legge, S., Leiper, I., Loyn, R., Murphy, B.P., Menkhorst, P., Reside, A.E., Ritchie, E.G., Roberts, F.E., Tingley, R., Garnett, S.T., 2018. Quantifying extinction risk and forecasting the number of impending Australian bird and mammal extinctions. Pacific Conserv. Biol. 24, 157-167.

Huey, R.B., Deutsch, C.A., Tewksbury, J.J., Vitt, L.J., Hertz, P.E., Héctor, J., Pérez, Á., Garland, T., Soc, P.R., 2009. Why tropical forest lizards are vulnerable to climate warming. Proc. R. Soc. Lond. B Biol. Sci. 276 https://doi.org/10.1098/rspb.2008.1957

IUCN, 2012. IUCN Red List Categories and Criteria. Version 3.1 Second edition. International Union for Conservation of Nature, Species Survival Commission, Switzerland.

IUCN, 2018. The IUCN Red List of Threatened Species. Version 2018-2. http://www.iucnredlist.org. Downloaded on 14 November 2018.

Kearney, S.G., Adams, V.M., Fuller, R.A., Possingham, H.P., Watson, J.E.M., 2018. Estimating the benefit of well-managed protected areas for threatened species conservation. Oryx 1-9. https://doi.org/DOI: 10.1017/S0030605317001739

Lunney, D., Hope, B., Shannon, I., 2017. Protect our protected areas!: the value of protected areas for fauna research and conservation, a case study of New South Wales. Aust. Zool. 39, 296-344. https://doi.org/10.7882/AZ.2017.036

Maritz, B., Penner, J., Martins, M., Crnobrnja-Isailović, J., Spear, S., Alencar, L.R. V, SigalaRodriguez, J., Messenger, K., Clark, R.W., Soorae, P., Luiselli, L., Jenkins, C., Greene, H.W., 2016. Identifying global priorities for the conservation of vipers. Biol. Conserv. 204, 94-102. https://doi.org/https://doi.org/10.1016/j.biocon.2016.05.004

Meiri, S., 2016. Small, rare and trendy: traits and biogeography of lizards described in the $21 \mathrm{st}$ century. J. Zool. 299, 251-261. https://doi.org/10.1111/jzo.12356

Meiri, S., Chapple, D.G., 2016. Biases in the current knowledge of threat status in lizards, and bridging the 'assessment gap.' Biol. Conserv. 204, 6-15. https://doi.org/10.1016/j.biocon.2016.03.009

Reed, R.N., Shine, R., 2002. Lying in wait for extinction: ecological correlates of conservation status among Australian elapid snakes. Conserv. Biol. 16, 451-461. https://doi.org/10.1046/j.15231739.2002.02283.x

Ringma, J., Legge, S., Woinarski, J.C.Z., Radford, J.Q., Wintle, B., Bentley, J., Burbidge, A.A., Copley, P., Dexter, N., Dickman, C.R., Gillespie, G.R., Hill, B., Johnson, C.N., Kanowski, J., Letnic, M., Manning, A., Menkhorst, P., Mitchell, N., Morris, K., Moseby, K., Page, M., Palmer, R., Bode, M., 2019. Systematic planning can rapidly close the protection gap in Australian 
mammal havens. Conserv. Lett. 12, e12611. https://doi.org/10.1111/conl.12611

Rosauer, D.F., Blom, M.P.K., Bourke, G., Catalano, S., Donnellan, S., Gillespie, G., Mulder, E., Oliver, P.M., Potter, S., Pratt, R.C., Rabosky, D.L., Skipwith, P.L., Moritz, C., 2016. Phylogeography, hotspots and conservation priorities: an example from the Top End of Australia. Biol. Conserv. 204, 83-93. https://doi.org/https://doi.org/10.1016/j.biocon.2016.05.002

Saha, A., McRae, L., Dodd, C.K., Gadsden, H., Hare, K.M., Lukoschek, V., Böhm, M., 2018. Tracking global population trends: population time-series data and a Living Planet Index for reptiles. J. Herpetol. 52, 259-268.

Sinervo, B., Méndez-de-la-Cruz, F., Miles, D.B., Heulin, B., Bastiaans, E., Villagrán-Santa Cruz, M., Lara-Resendiz, R., Martínez-Méndez, N., Calderón-Espinosa, M.L., Meza-Lázaro, R.N., Gadsden, H., Avila, L.J., Morando, M., De la Riva, I.J., Victoriano Sepulveda, P., Rocha, C.F.D., Ibargüengoytía, N., Aguilar Puntriano, C., Massot, M., Lepetz, V., Oksanen, T. a, Chapple, D.G., Bauer, A.M., Branch, W.R., Clobert, J., Sites, J.W., 2010. Erosion of lizard diversity by climate change and altered thermal niches. Science 328, 894-899. https://doi.org/10.1126/science.1184695

Slavenko, A., Tallowin, O.J.S., Itescu, Y., Raia, P., Meiri, S., 2016. Late Quaternary reptile extinctions: size matters, insularity dominates. Glob. Ecol. Biogeogr. 25, 1308-1320. https://doi.org/10.1111/geb.12491

R Development Core Team, 2018. R: A language and environment for statistical computing. Vienna, Austria.

Tingley, R., Hitchmough, R.A., Chapple, D.G., 2013. Life-history traits and extrinsic threats determine extinction risk in New Zealand lizards. Biol. Conserv. 165, 62-68. https://doi.org/http://dx.doi.org/10.1016/j.biocon.2013.05.028

Tingley, R., Meiri, S., Chapple, D.G., 2016. Addressing knowledge gaps in reptile conservation. Biol. Conserv. 204, 1-5. https://doi.org/10.1016/j.biocon.2016.07.021

Tolley, K.A., Alexander, G.J., Branch, W.R., Bowles, P., Maritz, B., 2016. Conservation status and threats for African reptiles. Biol. Conserv. 204, 63-71. https://doi.org/https://doi.org/10.1016/j.biocon.2016.04.006

Tolley, K.S., Weeber, J., Maritz, B., Verburgt, L., Bates, M.F., Conradie, W., Hofmeyr, M.D., Turner, A.A., da Silva, J.M., Alexander, G.J., 2019. No safe haven: protection levels show imperilled South African reptiles not sufficiently safe-guarded despite low average extinction risk. Biol. Conserv. 233, 61-72. https://doi.org/10.1016/j.biocon.2019.02.006

Tonini, J.F.R., Beard, K.H., Ferreira, R.B., Jetz, W., Pyron, R.A., 2016. Fully-sampled phylogenies of squamates reveal evolutionary patterns in threat status. Biol. Conserv. 204, $23-31$. https://doi.org/https://doi.org/10.1016/j.biocon.2016.03.039

Watson, J.E.M., Evans, M.C., Carwardine, J., Fuller, R.A., Joseph, L.N., Segan, D.A.N.B., Taylor, 
661

662

663

664

665

666

667

668

669

670

671

672

673

674

675

676
M.F.J., Fensham, R.J., Possingham, H.P., 2011. The Capacity of Australia's Protected-Area System to Represent Threatened Species. Conserv. Biol. 25, 324-332. https://doi.org/10.1111/j.1523-1739.2010.01587.x

Woinarski, J.C.Z., Burbidge, A.A., Harrison, P.L., 2015. Ongoing unraveling of a continental fauna: Decline and extinction of Australian mammals since European settlement. Proc. Natl. Acad. Sci. 112, 4531 LP-4540. https://doi.org/10.1073/pnas.1417301112

Woinarski, J.C.Z., Burbidge, A.A., Harrison, P.L., 2014. The action plan for Australian mammals 2012. CSIRO Publishing, Collingwood.

Woinarski, J.C.Z., Murphy, B.P., Palmer, R., Legge, S.M., Dickman, C.R., Doherty, T.S., Edwards, G., Nankivell, A., Read, J.L., Stokeld, D., 2018. How many reptiles are killed by cats in Australia? Wildl. Res. 45, 247-266.

Woinarski, J.C.Z., 2018. The extent and adequacy of monitoring for Australian threatened reptile species, In Monitoring threatened species and ecological communities eds S. Legge, D.B. Lindenmayer, N.M. Robinson, B.C. Scheele, D.M. Southwell, B.A. Wintle, pp. 69-84. CSIRO Publishing, Clayton. 
677 Table 1. Number of terrestrial Australian squamates in each IUCN conservation status category.

\begin{tabular}{lll}
\hline Category & Percentage of species & $\mathbf{N}$ \\
\hline Extinct & 0.1 & 1 \\
Extinct in the Wild & 0.2 & 2 \\
Critically Endangered & 1.1 & 10 \\
Endangered & 2.7 & 26 \\
Vulnerable & 3.0 & 28 \\
Near Threatened & 2.0 & 19 \\
Least Concern & 86.4 & 819 \\
Data Deficient & 4.5 & 43 \\
\hline
\end{tabular}

678 
Table 2. Number of terrestrial Australian squamates within each taxonomic family and IUCN conservation status category. Optimistic estimates of the percentage of threatened species assume that DD species are not threatened; pessimistic estimates assume that all DD species are threatened.

682

Family

Percentage Percentage

LC NT VU EN CR EW EX DD Total threatened threatened (optimistic) (pessimistic)

Acrochordidae

$\begin{array}{lllllllll}1 & 0 & 0 & 0 & 0 & 0 & 0 & 0 & 1\end{array}$

0

Agamidae

Carphodactylidae

$\begin{array}{lllllllll}22 & 3 & 2 & 2 & 1 & 0 & 0 & 0 & 30\end{array}$

17

Colubridae

$\begin{array}{lllllllll}4 & 0 & 0 & 0 & 0 & 0 & 0 & 0 & 4\end{array}$

0

0

Diplodactylidae

$\begin{array}{lllllllll}85 & 2 & 3 & 1 & 0 & 0 & 0 & 2 & 93\end{array}$

4

6

Elapidae

952

Gekkonidae

43

1

$\begin{array}{lllll}0 & 0 & 0 & 5 & 106\end{array}$

4

8

Homalopsidae

Natricidae

$\begin{array}{llll}1 & 0 & 0 & 0\end{array}$

$\begin{array}{lllll}0 & 1 & 0 & 1 & 47\end{array}$

6

Pygopodidae

1

$\begin{array}{lllll}0 & 0 & 0 & 0 & 1\end{array}$

0

Pythonidae

Scincidae

36

$\begin{array}{llll}36 & 1 & 1 & 3\end{array}$

$\begin{array}{llll}0 & 0 & 0 & 1\end{array}$

0

0

Typhlopidae

$\begin{array}{llll}13 & 0 & 1 & 0\end{array}$

$\begin{array}{llll}0 & 0 & 3 & 44\end{array}$

9

16

Varanidae

$\begin{array}{llll}379 & 10 & 15 & 13\end{array}$

0

$0 \quad 14$

7

$\begin{array}{llllllllll}35 & 0 & 0 & 1 & 1 & 0 & 0 & 8 & 45 & 4\end{array}$

$\begin{array}{lllllllll}28 & 0 & 0 & 1 & 1 & 0 & 0 & 1 & 31\end{array}$

6 


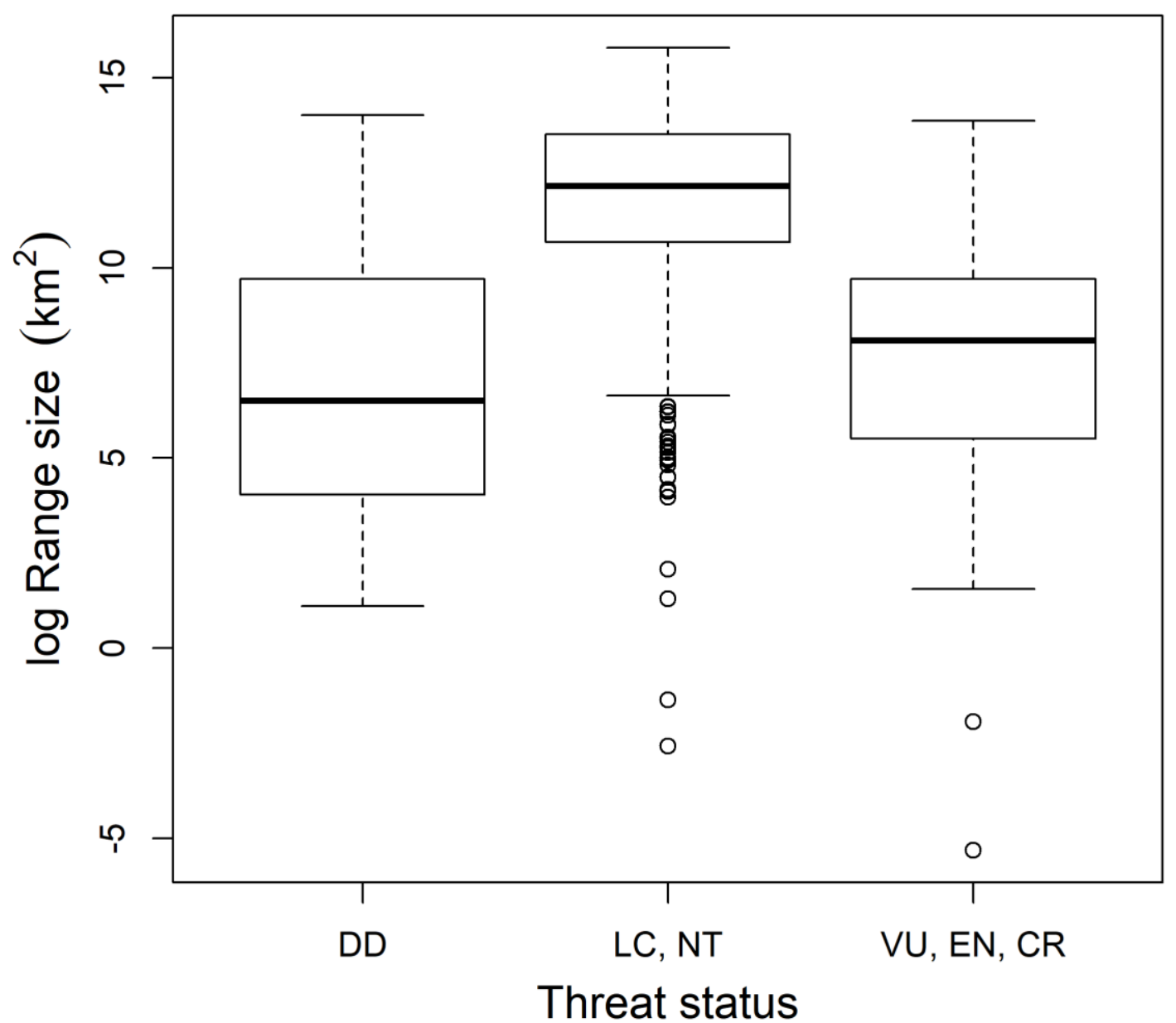

Fig. 1. Geographical range size (ln-transformed) of Data Deficient (DD), non-threatened (LC, NT) and threatened (VU, EN, CR) species. Note that only Australian portions of a species' range are included. 


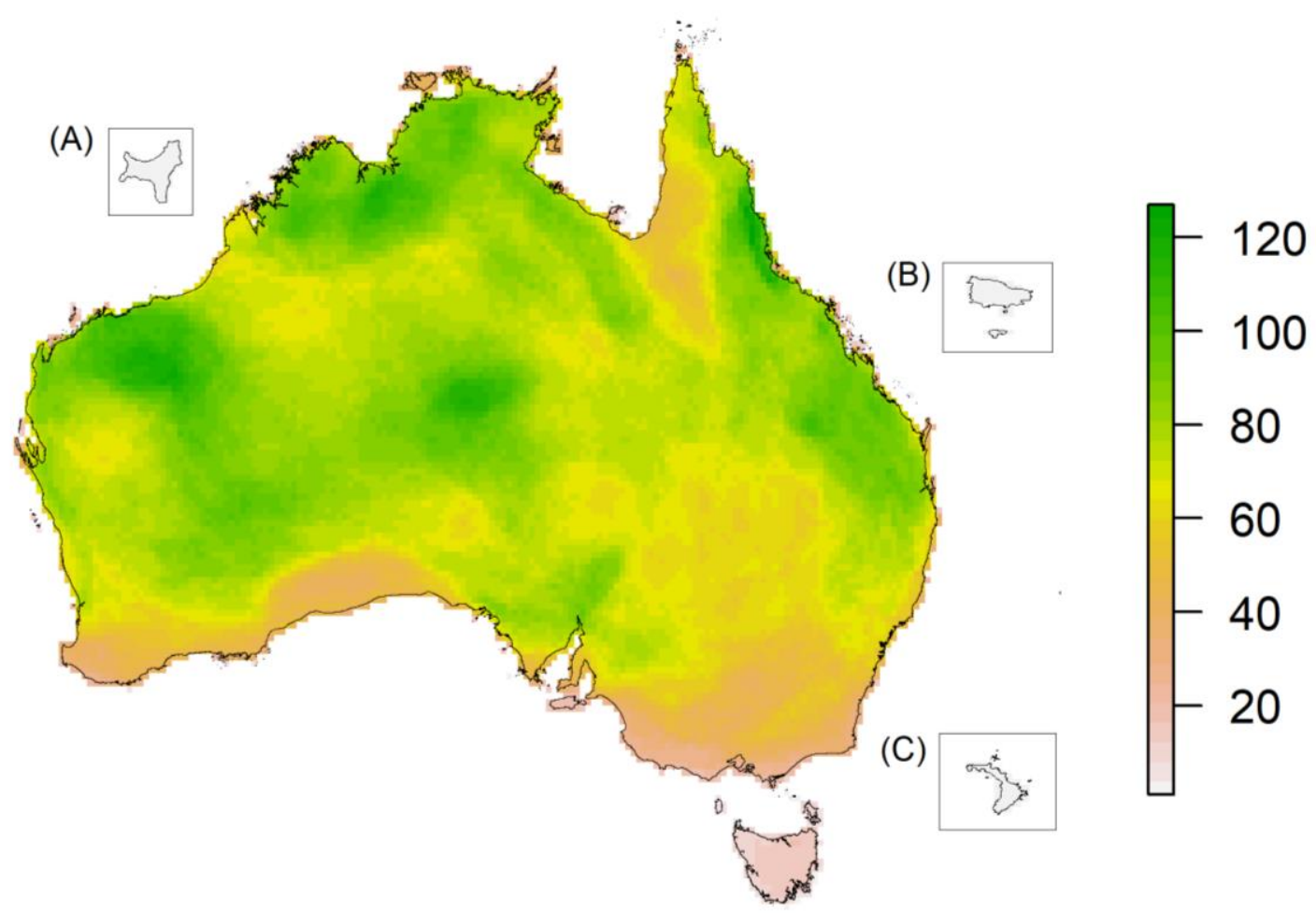

Fig. 2. Species richness of Australian squamates. Insets (not to same scale) show Christmas Island (A), Norfolk Island group (B), and Lord Howe Island group (C). 


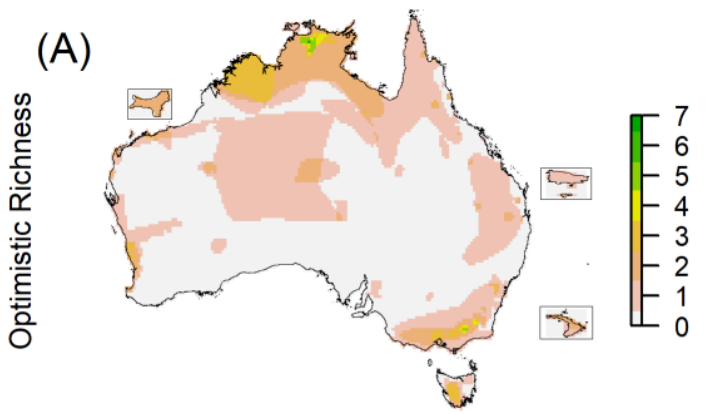

(B)
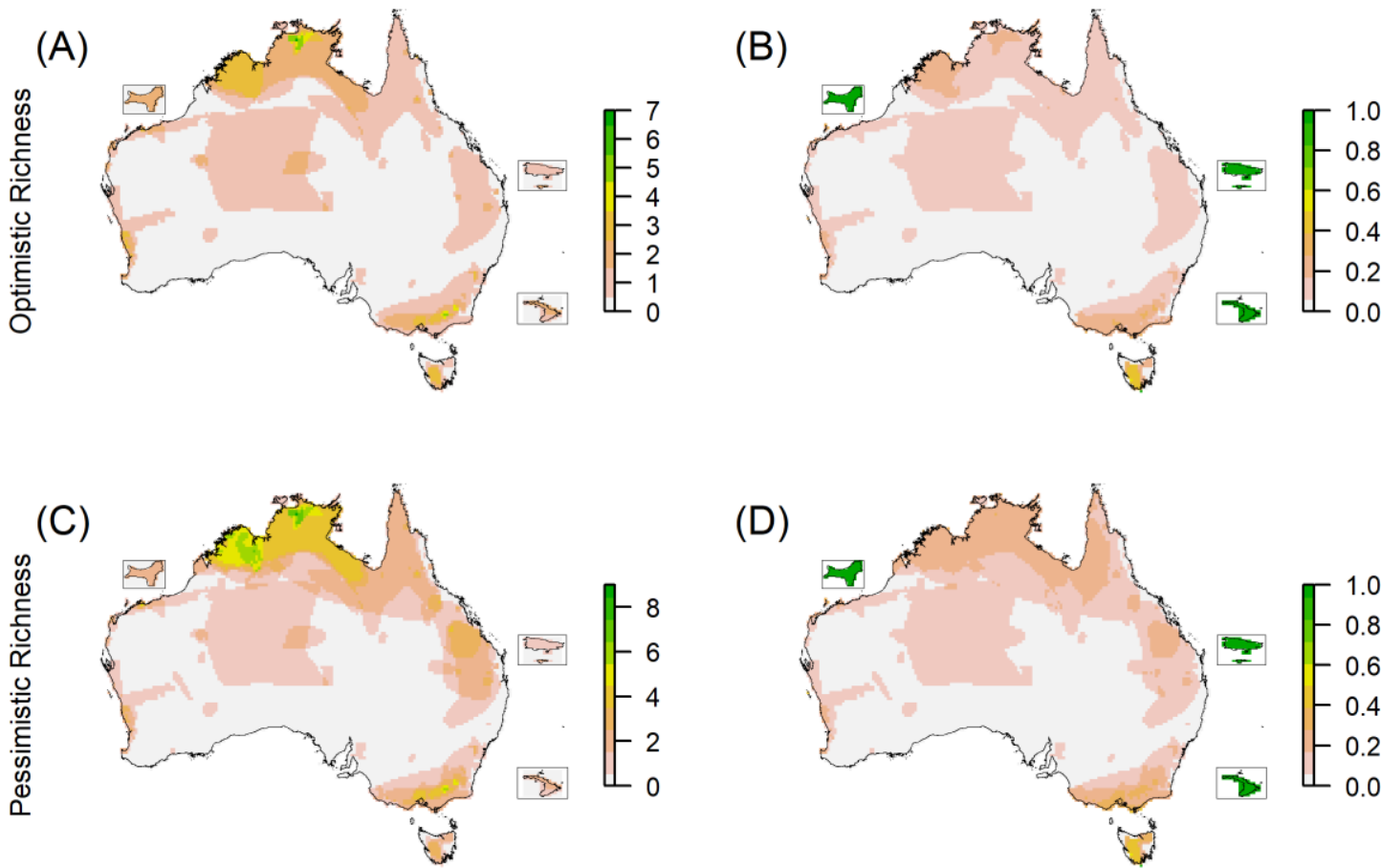

(D)
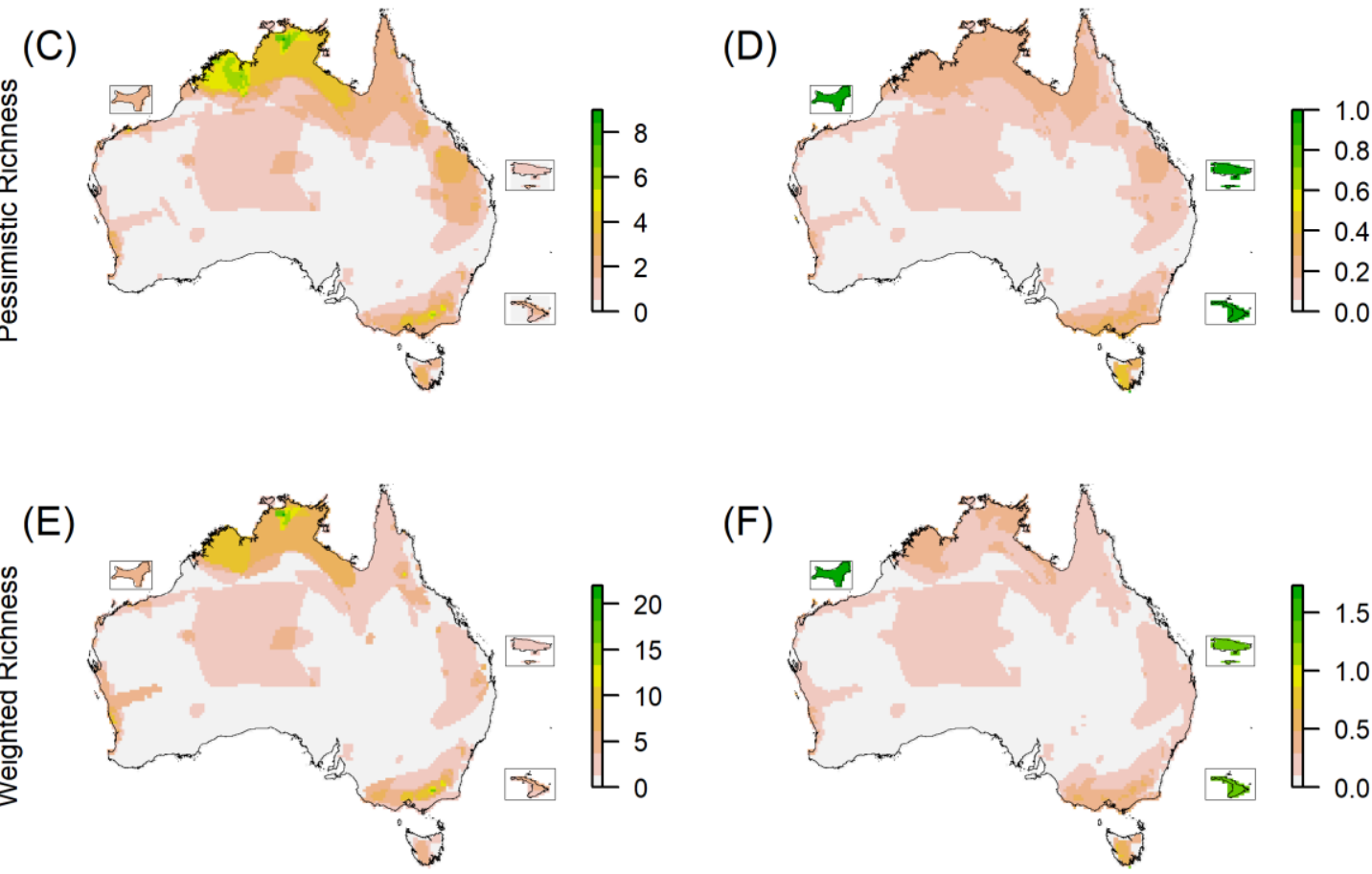

(F)

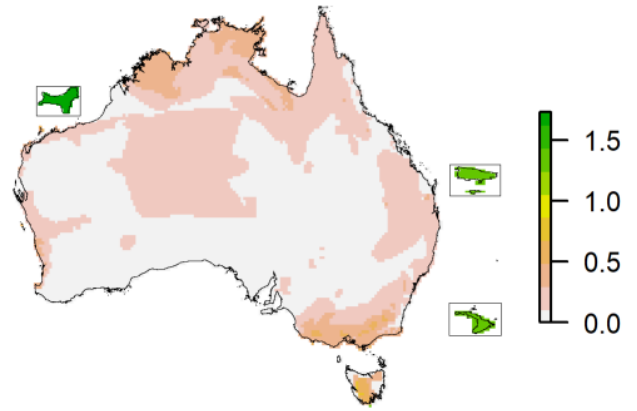

Fig. 3. Species richness of threatened Australian squamates under different assumptions. Panels (A) and (C) make optimistic and pessimistic assumptions, respectively, about the threat status of Data Deficient species (see Methods for details). Panels (B) and (D) represent the same data presented in (A) and (C), expressed as a proportion of absolute species richness (square-root transformed). Panels (E) and (F) represent weighted conservation status sums and weighted conservation status means, respectively, calculated by assigning continuous values to IUCN conservation status categories: $0=\mathrm{LC}, 1=\mathrm{NT}, 2=\mathrm{VU}, 3=\mathrm{EN}, 4=\mathrm{CR}$. Islands shown in inset maps are the same as those in Fig. 1. 
(A) DD Richness

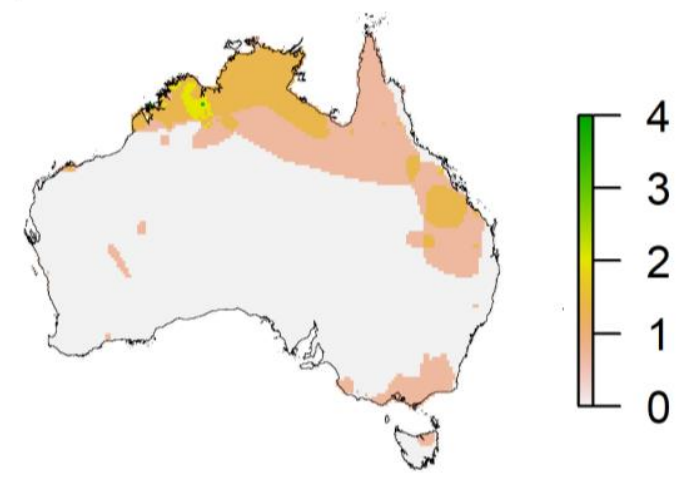

(B) Proportional DD Richness

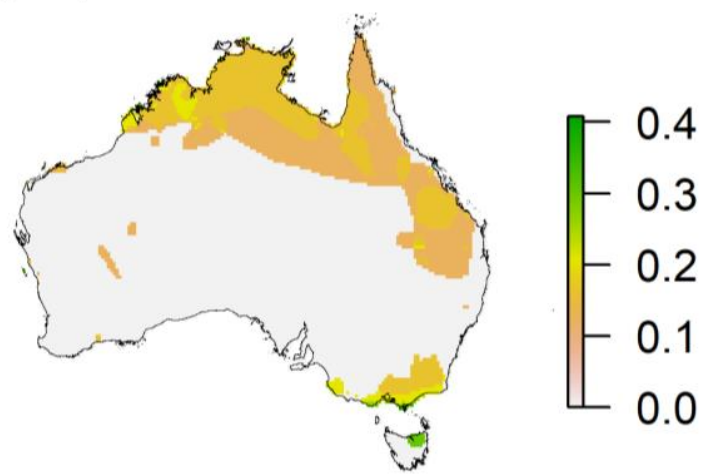

Fig. 4. Species richness of Data Deficient squamates (A), and of Data Deficient squamates expressed as a proportion of absolute species richness (B). Note that values in panel (B) are square-roottransformed to improve clarity. 


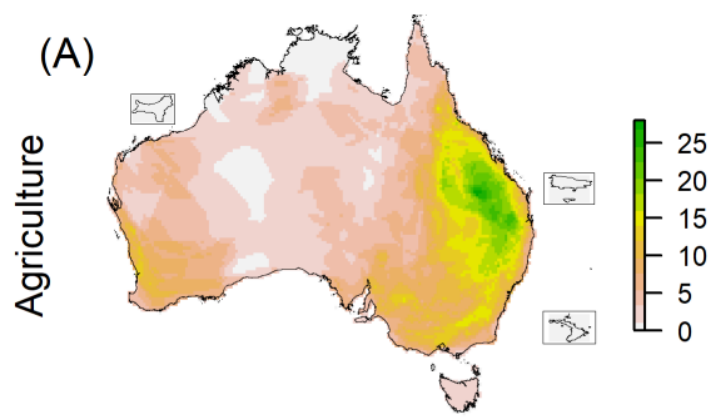

(B)
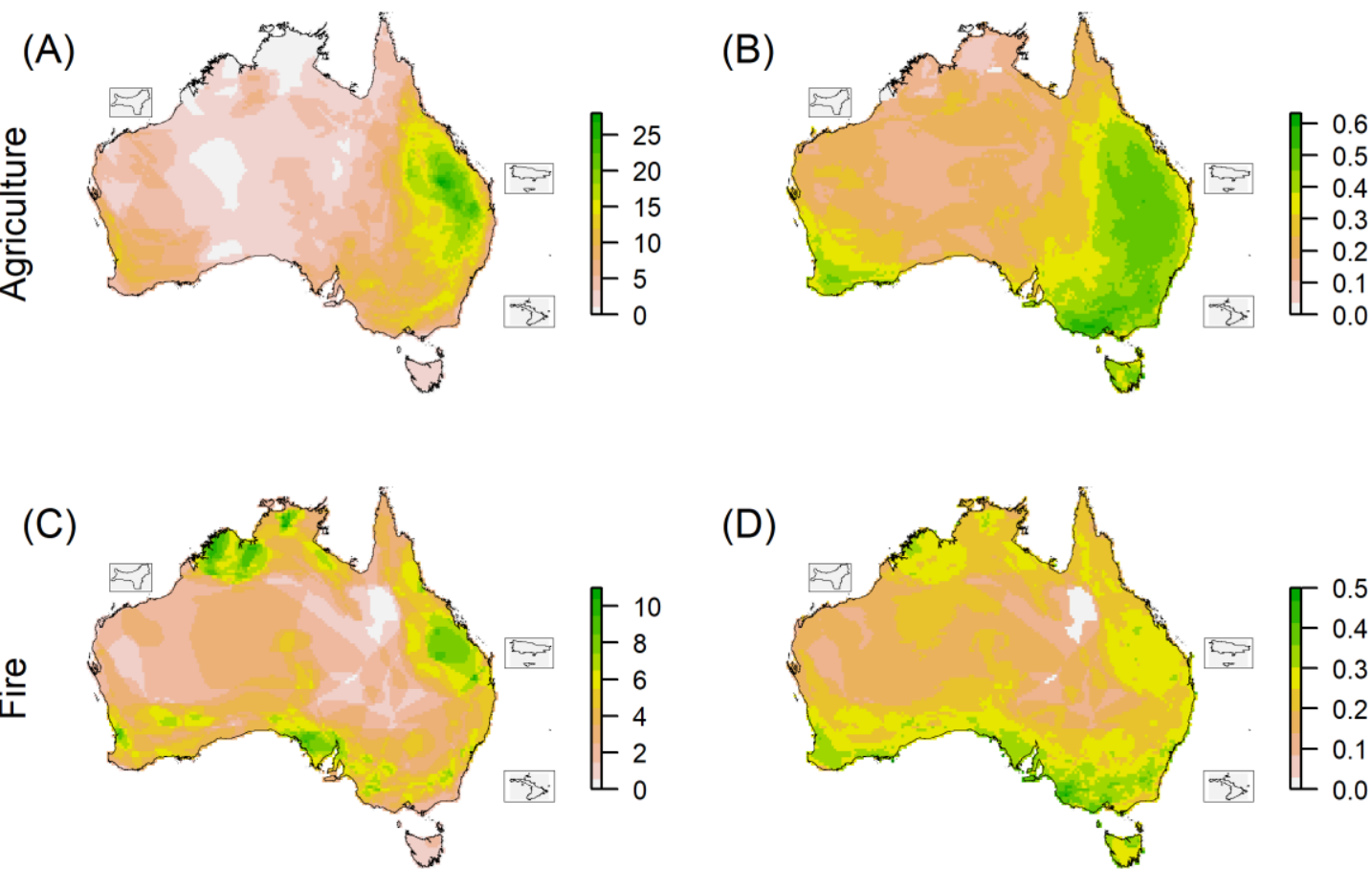

(D)
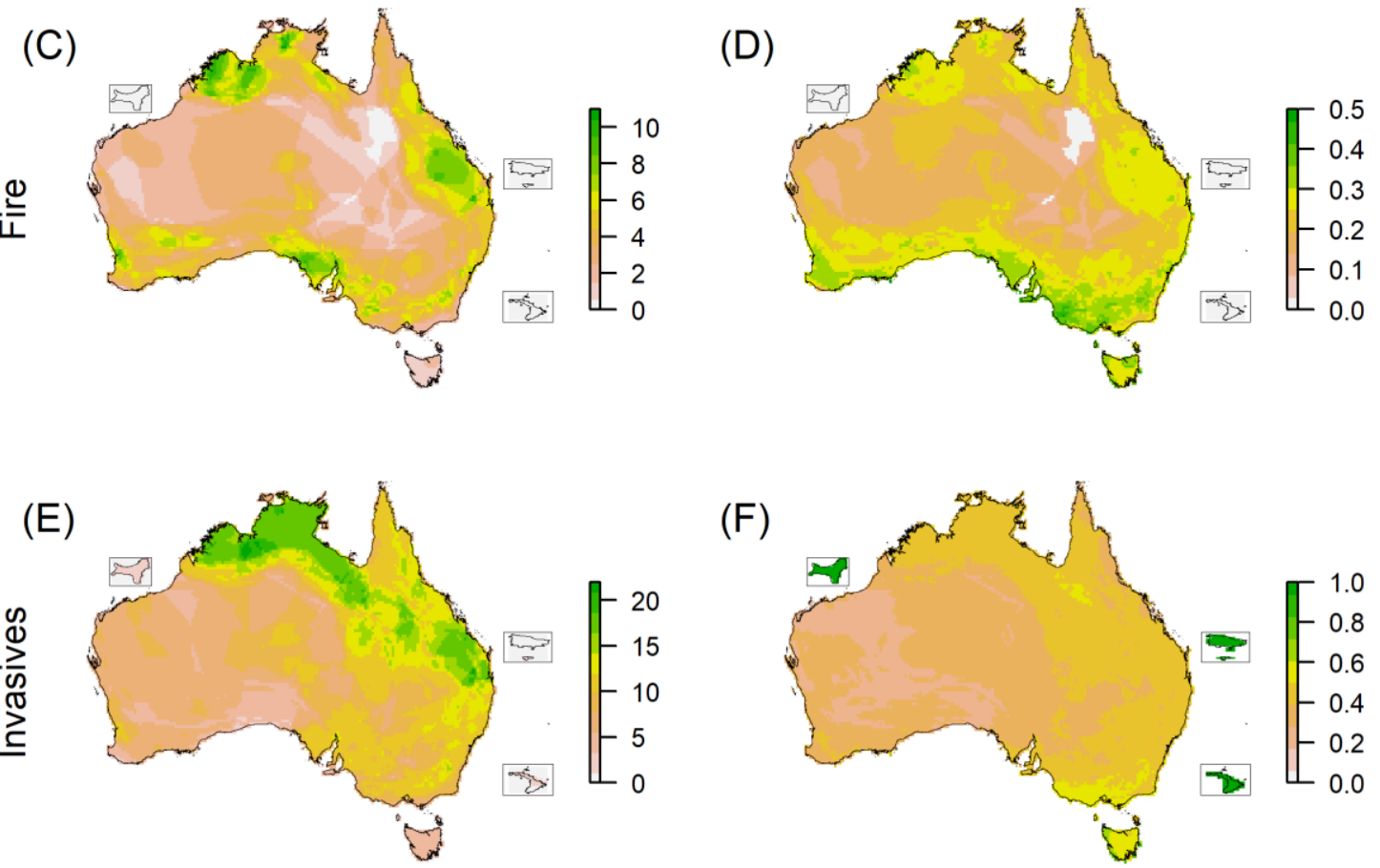

Fig. 5. The number of Australian squamate species affected by different threat types. Panels on the left show the numbers of species affected by agriculture (A), fire (C), and invasive and other problematic species and diseases (E). Panels (B), (D), and (F) represent the same data presented in (A), (C), and (E), expressed as a proportion of absolute species richness (square-root-transformed). 